И. 3. Чимитова. Проблема прав человека в мультикультурном обществе

\author{
Научная статья \\ УДК 1: 34 \\ DOI: $10.18101 / 1994-0866-2021-2-61-69$
}

\title{
ПРОБЛЕМА ПРАВ ЧЕЛОВЕКА В МУЛЬТИКУЛЬТУРНОМ ОБЩЕСТВЕ
}

\author{
(C) Чимитова Ирина Зоригтоевна \\ кандидат социологических наук, и. о. доцента, \\ Бурятская государственная сельскохозяйственная академия им. В. Р. Филиппова \\ Россия, 670024, г. Улан-Удэ, ул. Пушкина, 8 \\ rindaol@mail.ru
}

\begin{abstract}
Аннотация. Понятие «мультикультурализм» активно используется более полувека, но актуализировалось в последние десятилетия. В мультикультурном обществе отношения контактирующих сторон должны строиться в парадигме достижения все большего равенства их прав и возможностей, диалектики прав человека и его ответственности, сохранения идентичности этнических групп и их сосуществования, основанных на концепте прав человека, неразрывно связанном с требованием ко всем жителям соблюдать законодательство и общепринятые правила. Успех межкультурного диалога зависит и от способности его участников исходить из установки на принципиальную дополнительность взаимодействующих культур. Мультикультурной страной является и Россия. Культуры населяющих ее народов издавна взаимно обогащают друг друга, а многие их элементы стали общим достоянием. В настоящее время заметную часть приезжих составляют мигранты из постсоветской Центральной Азии, адаптация которых все успешнее регулируется как законодательством, так и процессами их самоорганизации. Мультикультурная Республика Бурятия с многовековыми прочными традициями толерантности и согласия между народами является благоприятным для инокультурных мигрантов регионом.
\end{abstract}

Ключевые слова: мультикультурализм, права человека, законодательство, мигрант, принимающее общество, этническая группа, дополнительность культур

\section{Для цитирования}

Чимитова И. 3. Проблема прав человека в мультикультурном обществе // Вестник Бурятского государственного университета. Философия. 2021. Вып. 2. С. 61-69.

Понятие мультикультурализма как способа сосуществования представителей разных этнических культур в границах одного общества, разрешения противоречий между ними и достижения взаимоприемлемого баланса их интересов стали активно использовать в 60-х — начале 70-х гг. XX в. сначала в Канаде, затем в Австралии. Вскоре им стали обозначать и процессы, обусловленные расширением миграционного потока в страны Западной Европы. Между тем мультикультурализм проявлялся уже в глубокой древности и наблюдается сегодня в зонах взаимодействия народов и пересечения их культур.

Существует множество вариантов мультикультурализма: сложившегося исторически или относительно недавно, объединяющего несколько коренных народов или коренное население и группы инокультурных мигрантов и т. д. Современный мультикультурализм в ряде государств и регионов мира (Северная Америка, Австралия, объединенная Европа и др.) особенно часто обсуждается 
как один из способов интеграции иноэтничных приезжих в принимающее общество.

Применительно к странам Западной Европы в течение некоторого периода этот феномен в интерпретации общественности коренного происхождения связывался с позитивными коннотациями гуманного отношения к выходцам из бывших колоний, людям, находящимся в трудных и критических обстоятельствах, готовностью принимающего населения помогать мигрантам и т. п.

В начале нынешнего столетия этот концепт, сопряженный с проблематикой глобалистики, приобрел значимость одного из самых актуальных и обсуждаемых вопросов социально-гуманитарного дискурса. В некоторых научных публикациях подчеркивается естественность и необходимость сохранения идентичности мигрантов, приветствуется (особенно это относится к работам по социальной философии, эстетике, культурологии, этнологии и ряду других научных дисциплин) как ценность этнокультурное разнообразие.

В русле этого подхода - понимание мультикультурализма, в котором подчеркивается «возможность автономного развития разных общностей в рамках одного общества, сохранение разнообразия... ценностей и идеалов, способов организации жизненного пространства» [1, с. 130].

К сожалению, на практике автономность нередко оказывается неоднозначным явлением: наряду с приверженностью части мигрантов этническим традициям она проявляется и в форме параллельного существования приезжих и коренных, миры которых подчас почти не соприкасаются, в изоляционизме первых, их индифферентности к нормам и ценностям нового окружения, а порой и в их активном неприятии и отторжении. О некоторых проявлениях такой реакции в аспекте конфликтности в городской полиэтничной среде Д. В. Трофименко пишет: «В некоторых случаях возникают полузакрытые локальные группы, которые заражаются идеологиями религиозного радикализма и политического экстремизма... Исламистские сообщества в западных мегаполисах, к примеру, в Лондоне и Нью-Йорке, а также в городах республик Юга России часто открыто отвергают городские постиндустриальные ценности... поведения» [2, с. 3].

Нередко реальностью оказывается несовпадение культурных кодов обеих взаимодействующих сторон, нежелание части мигрантов интегрироваться в новую среду, их стремление замыкаться в этнических гетто, недовольство некоторых групп коренного населения системой преференций, получаемых вновь прибывшими и т. д.

Автономное существование одной стороны, имеющей не очень много сходства с другой (у которой, принявшей в свой состав первую, аналогичной возможности жить автономно нет уже по определению), без ущерба для сохранения идентичности второй стороны и сущностных качеств принимающего государства в целом возможно только до момента (грани), после которого нарушается комфортное бытие второй стороны на уже общей для всех территории.

Этим обусловлены не вполне одобрительные оценки этнокультурной мозаичности ряда стран Запада, высказываемые рядом специалистов по миграционным процессам. Так, в одной из публикаций об этнокультурной гетерогенности приезжих говорится о таком явлении, которое нужно преодолевать: «этнокультурная 
гетерогенность преодолевается гораздо труднее, чем гетерогенность социальная...» [3, с. 117].

Полагаем, что преодоление этнокультурной мозаичности малоперспективно и едва ли возможно в ближайшем будущем, однако при этом в условиях диссонанса этнокультурных кодов сторон в политике мультикультурализма не всегда целесообразен акцент на автономности культур, ведущий к отмеченным выше последствиям.

В большинстве ситуаций необходимо всемерно актуализировать концепт прав человека, сделать его ключевым, в частности, это касается отдельных социально-экономических прав граждан принимающей страны: упомянутая выше система преференций для мигрантов ставит некоторых коренных жителей в неравные условия с ними, ущемляя тем самым, например, права этих членов принимающего общества на социальное обеспечение, достойный жизненный уровень и т. п., сформулированные в Международном билле о правах человека и ряде европейских международно-правовых документов, принятых и общепризнанных мировым сообществом.

В свою очередь, нередко и мигранты обладают ограниченными возможностями для реализации своих прав. Так, в сфере труда шанс занять вакансию порой неотрывен от наличия у соискателя гражданства страны пребывания. Ущемлены в правах даже старожилы некоторых стран, возникших на руинах СССР, по разным причинам не отвечающие некоторым новым требованиям постсоветского времени, к примеру, обладающие слабой обучаемостью языку коренного народа, а, возможно, иностранным языкам вообще. Подобные факты отчасти объясняются объективными причинами: отсутствием давних демократических традиций в странах СНГ, низкой правовой культурой населения, слабостью гражданского общества, в том числе правозащитного движения, недостаточной прочностью правового государства и др.

Даже страны Западной Европы, будучи первооткрывателями проблематики прав человека и имея в активе богатые гуманистические традиции, начиная с Beликой хартии вольностей 1215 г., сталкиваются с трудностями в правовом регулировании отношений приезжих и принимающего общества, в том числе с «отсутствием единого определения понятия "мигрант"»; ...единого механизма реагирования на угрозы иммиграции; несовершенством законодательства и мер по адаптации иммигрантов к условиям труда, быта и культуры страны их пребывания и т.д.» [4, с. 125-126]. Встречаются и проявления бытовой ксенофобии, когда некоторые европейцы относятся к мигрантам «с неприязнью, всячески ущемляя их права и возможности» [5, с. 668].

В мультикультурном обществе, по сути, взаимодействие сторон должно быть выстроено в парадигме достижения все большего равенства их прав и возможностей, диалектики свободы и необходимости, прав человека и его ответственности, сохранения идентичности всех групп и их сосуществования, которые предполагают в качестве фундамента концепт прав человека, неразрывно связанный с требованием ко всем соблюдать законы, принимать другие базовые нормы и правила. 
Необходимо учитывать интересы и потребности как коренного населения, так и пришлого, выстраивать управленческие решения властей принимающих стран и их гражданского общества, направленные на диалог с лидерами диаспор, разными сегментами мигрантского сообщества и т. д.

Фактов, подтверждающих действенность этой модели, много, особенно в странах Западной и Северной Европы и Северной Америки, «где реально обеспечены гражданские права. Просто иммигранты и меньшинства, как и все, использовали неприкосновенность частной собственности, возможности ведения бизнеса, право на ассоциации, право на свободу выражения, религиозные свободы, право распространять информацию, в том числе создавать средства массовой информации» [6, с. 21]. Демократическое общество распространяет принцип уважения прав и человеческого достоинства и на нелегальных мигрантов, расширяя их права и предоставляя им определенные преимущества [7, с. 91].

Достижению взаимоприемлемых условий способствует утверждение позиции, согласно которой «можно говорить о мультикультурализме, когда мы обнаруживаем не только желание этнических групп адаптироваться к принимающему обществу, но и стремление принимающего общества и государства адаптировать (но не ассимилировать) этнические группы, сохраняя их культурную идентичность» $[8$, с. 198].

Тем самым реализуется один из желательных для общества в целом сценариев его (а также составляющих его групп и индивидов) реагирования на ситуацию мультикультурализма: «Формируется специильная правовая база, гарантирующзая каждому субъекту соблюдение его прав. Признание меньшинства влечет за собой административные последствия, например, создание фондов, выделяющих средства на нужды меньшинств. Отношения между группами и индивидами регулируются правовыми нормами, законодательством, являющимся результатом признания различий» $[9$, с. 61$]$.

Иначе говоря, во главу угла ставится готовность контактирующих сторон продвигаться навстречу друг к другу, вступать в диалог. Его успех зависит и от способности обеих сторон исходить из установки на принципиальную дополнительность взаимодействующих на данной территории разных культур. Развивая теорию Н. Бора, Т. П. Григорьева писала: что «специфическое... есть проявление общего, общечеловеческого: последнее составляет сущность первого. И сущность эта не в простой совокупности всех эмпирических фактов и явлений, а в каждом из них или, как говорят поэты, в капле росы отражается мир. Один цвет не создает спектра, одно крыло не дает полета; там, где одно и то же, там нет развития. Обнаруживая в малоизученных культурах новые черты, мы полнее постигаем собственную культуру» [10, с. 18-19].

Идею дополнительности Запада и Востока в целях глобального устойчивого развития выражает Л. В. Мантатова, предлагая «дополнить технократизм Запада духовностью Востока, а права и свободу человека - "восточным духом"» святости бытия. Мир творится разнообразием культур и обретает единство в глобальной цивилизации» $[11$, с. 28$]$.

Однако помимо идейного посыла и базовых принципов в реальной жизни всегда важен контекст общения, в котором, на наш взгляд, роль отправного 
пункта должны играть элементы сугубо внешнего порядка, не требующие ни глубокого познания друг друга, ни уверенного владения языком, ни особой эмпатии - элементарные правила вежливости. Они могут выступать в качестве стартовой позиции дальнейшего выстраивания стратегии взаимоприемлемого урегулирования отношений. Добиваться согласия мигрантов в лице лидеров их сообществ, соблюдать внешние формы культуры поведения, принятой в стране пребывания, их готовность следовать элементарному этикету должны представители официальных властей: работники миграционных, социальных и т. п. служб, проявляя соответствующие профессиональные и человеческие качества, умения и навыки, в том числе и присущие людям высокой культуры. Такое согласие основа дальнейших отношений: оно может послужить первым шагом к тому, чтобы приезжие интегрировались в принимающее общество.

При этом сохраняется суть принципа мультикультурализма, но принимается во внимание разница культурных кодов сторон, акцент делается на способности контактирующих групп проявлять сдержанность, демонстрировать воспитанность, цивилизованность независимо от наличия качества, которое Л. Н. Гумилев называл комплементарностью. «Мультикультурализм как реальность, - отмечает Е. В. Хлыщева, - возможен при высоком уровне как личностного, так и государственного сознания» $[12$, с. 56$]$.

В русле упомянутого выше подхода и соответствующей модели мультикультурализма австралийский исследователь Е. Зубжицки, отмечая многогранность этого понятия, так раскрывает его: «Термин "мультикультурализм" многоплановый и включает в себя множество форм добровольных контактов между культурами, приводящих к образованию новой дифференцированной культуры. В Австралии это проявляется при формировании на основе более чем ста этнических меньшинств новой национальной общности, в которую войдут все, начиная от аборигенов и кончая самыми последними беженцами, прибывшими из Афганистана и Ирака и просящими политического убежища» [цит. по: 9, с. 60].

Россия также является мультикультурной страной, причем с многовековыми традициями, обусловившими взаимное проникновение и обогащение культур ее народов и создание такого феномена, как общероссийская культура. В отличие от ряда других современных государств российские культуры имеют много зон пересечения и более того - реальной общности, когда трудно определить достоянием культуры какого-то конкретно этноса является та или иная культурная ценность. Ни ислам, ни буддизм, ни многие иные вероучения не чужеродны для отечественной культуры. В. А. Тишков справедливо подчеркивает долговременный характер совместного проживания носителей многих культур и языков на ее территории и в составе одного российского народа: «Многообразие населения стало источником постоянного и взаимообогащающего общения, условием развития страны. Трудно вообразить, что представляло бы собой российское государство, если бы оно развивалось столетиями только на территориальной, демографической и культурной основе одного или нескольких восточнославянских племен» [13, с. 17].

Что касается довольно заметной доли трудовых иммигрантов и их семей, в основном из новых стран Центральной Азии, то у части из них, главным образом, 
старшего и среднего возраста, наличествует фактор общего с россиянами прошлого, а также общего языка, что обеспечивает быструю интеграцию в принимающее общество этого сегмента приезжих. При этом языковые компетенции в основном пропорциональны возрасту человека. Но этот фактор по естественным причинам с каждым годом теряет свою значимость: старшее поколение уходит из жизни или в силу возраста теряет мобильность. Поэтому основная масса мигрантов из этого региона все больше характеризуется слабым владением русским языком и столь же слабым знанием российских реалий. Тем не менее адаптация прибывших проходит, она все успешнее регулируется законодательством РФ, процессами самоорганизации и взаимопомощи приезжих и т. д. Разумеется, эти процессы протекают с поправкой на конкретные особенности и обстоятельства, зависят от уровня компетентности конкретных представителей власти и т. д.

Так, на российском рынке трудоустройство некоторых групп мигрантов сопряжено со значительными сложностями. Зачастую те, высокая квалификация которых подтверждается документами, выданными на родине, и стажем профессиональной деятельности, и даже те, кто занимал там престижные должности, на новом месте вынуждены довольствоваться малоквалифицированной работой. Например, «самыми невостребованными на российском рынке труда оказались относительно многочисленные группы занятых у себя дома в здравоохранении, образовании и государственном управлении. Только 6,3\% работавших в стране происхождения в здравоохранении заняты в этой сфере в РФ, еще ниже аналогичная доля работников образования $(2,8 \%)$ и государственного управления $(1,9 \%)$. В торговлю пошли трудиться $46,6 \%$ работавших в здравоохранении, $41,9 \%$ работников образования, треть $(34,3 \%)$ занятых в государственном управлении, в сферу коммунального и социального обслуживания - 12,6\% бывших работников здравоохранения, $12,4 \%$ - образования, $20 \%$ - государственного управления [14, с. 67].

Один из субъектов РФ, Республика Бурятия, является также мультикультурным регионом, где за века добрососедства и сотрудничества народов-старожилов сложились толерантность и согласие между ними как традиция и часть образа жизни, которые стали нормой и для представителей других народов, селившихся в разное время на ее территории [15].

Не случайно не только в России, но и в СНГ республика воспринимается как вполне возможная цель трудовой миграции, несмотря на проблемы экономического характера и низкий уровень жизни населения. Экспертный опрос представителей ряда этносов Бурятии, проведенный в 2017 г., показал «высокий уровень взаимной открытости» населения. При ответе на вопрос: «Какие взаимоотношения с представителями других национальностей для вас приемлемы?» большинство экспертов $(81,9 \%)$ указали на отношения личной дружбы и $80,17 \%$ респондентов выразили готовность быть с ними коллегами по работе [16, с. 173].

Эмпирические данные фиксируют нормальное самочувствие приезжих в республике: «они ощущают себя комфортно в нашем регионе. Этнокультурное взаимодействие с местными жителями характеризуется положительными отношениями, часть мигрантов получила от местных жителей помощь [17, с. 263-264]. 
На примере одной из центральноазиатских диаспор, кыргызской, П. К. Варнавский показывает адекватность политики местных властей по отношению к мигрантам, их стремление организовать коммуникации с ними в лице их лидеров и объединений, а также между представителями разных этнических групп и результативность этих усилий. «Не просто сосуществование, но и тесные взаимодействия между национально-культурными центрами, между ними и властью создают осязаемое почти физически пространство или «поле мультикультурализма», в котором этнические группы объективируются и становятся главными акторами социального пространства» [18, с. 124].

Таким образом, очевидна и актуальность, и многоаспектность проблемы мультикультурализма в современном глобальном мире. С возрастанием социальной динамики он все шире охватывает социальное пространство, своеобразно проявляясь в своих конкретных вариантах, в том числе и в условиях России и даже в таких ее отдаленных частях, как Республика Бурятия.

Литература

1. Толерантность и образование: современные проблемы формирования толерантного сознания: кол. монография / ответственный редактор А. В. Перцев. Екатеринбург: Полиграфист, 2006. Вып. 16. 192 с. Текст: непосредственный.

2. Трофименко Д. В. Городское сообщество: разрешение институциональных конфликтов: автореферат диссертации на соискание ученой степени кандидата социологических наук. Ростов-на-Дону, 2008. 17 с. Текст: непосредственный.

3. Карцов А. С. Права человека и толерантность // Политические исследования. 2010. № 6. С. 116-130. Текст: непосредственный.

4. Магомедова Д. М., Бийгишиева Д. Ш. Вопросы регулирования миграции в странах Европейского Союза // Закон и право. 2019. № 2. С. 124-126. Текст: непосредственный.

5. Аминов И. Р. Этнополитические конфликты в условиях поликультурной среды: от «арабской весны» до североатлантического миграционного кризиса // Вестник Башкирского университета. Философия, социология, культурология и политология. 2014. Т. 19, № 2. С. 666-669. Текст: непосредственный.

6. Осипов А. Что такое этническая дискриминация и что с ней можно сделать? Москва: Сова, 2012. 152 с. Текст: непосредственный.

7. Крутиков Я. О. Объединенная Европа: вызов со стороны нелегальной миграции // Вестник Бурятского государственного университета. Философия, социология, политология, культурология. 2015. Вып. 14. С. 89-93. Текст: непосредственный.

8. Карнаухова О. С. Мультикультурализм как парадигма постколониального развития (британская модель) // Личность. Культура. Общество. 2007. Т. 9, вып. 4(39). С. 196-204. Текст: непосредственный.

9. Щлиз А., Шчепаньски М. С. Социологический смысл мультикультурализма: является ли Польша мультикультурной // Социологические исследования. 2014. № 2(358). С. 58-67. Текст: непосредственный.

10. Григорьева Т. П. Японская художественная традиция. Москва: Наука, 1979. 368 с. Текст: непосредственный.

11. Мантатова Л. В. Межкультурный диалог в многонациональном обществе // Евразийский фронтир: проблемы взаимодействия культур в многонациональном обществе: сборник научных статей / научный редактор И. С. Болдонова. Улан-Удэ: Изд-во Бурят. гос. ун-та, 2012. С. 27-28. Текст: непосредственный. 
12. Хлыщева Е. В. Проблема толерантности в диалоге культур // Философские науки. 2008. № 4. С. 46-57. Текст: непосредственный.

13. Этническое и религиозное многообразие России / под редакцией В. А. Тишкова, В. В. Степанова. Москва: ИЭА РАН, 2017. 551 с. Текст: непосредственный.

14. Варшавская Е. Я., Денисенко М. Б. Мобильность иностранных работников на российском рынке труда // Социологические исследования. 2014. № 4(360). С. 63-73. Текст: непосредственный.

15. Чимитова И. З., Серебрякова Ю. А. Межэтническая толерантность и согласие как традиция Бурятии // Вестник Бурятского государственного университета. Философия. 2019. Вып. 4. С. 64-70. Текст: непосредственный.

16. Бильтрикова А. В. Факторы межнационального согласия: некоторые результаты экспертного опроса в Республике Бурятия // Республике Бурятия - 95 лет: сборник научных статей / научный редактор Б. В. Базаров. Улан-Удэ: Изд-во БНЦ СО РАН, 2018. С. 173-174. Текст: непосредственный.

17. Чукреев П. А., Саргаев А. В. Мигранты-интеллигенты и их роль в процессах социально-культурной и правовой адаптации иностранных граждан в российском обществе // Интеллигенция, ее гражданские позиции в современном мире: материалы XI Международной научной конференции: в 2 томах / ответственный редактор И. И. Осинский. Улан-Удэ: Изд-во Бурят. гос. ун-та, 2016. Т. 2. С. 258-266. Текст: непосредственный.

18. Варнавский П. К. Кыргызская диаспора в Улан-Удэ: этнизация мигрантской общины как реакция на контакт с принимающим обществом // Вестник БНЦ СО РАН. 2013. № 4(12). С. 117-129. Текст: непосредственный.

Статья поступила в редакцию 12.04.2021; одобрена после рецензирования 30.04.2021; принята к публикации 11.05.2021.

\section{HUMAN RIGHTS PROBLEM IN A CULTURAL SOCIETY}

\section{Irina Z. Chimitova}

Cand. Sci. (Sociol.), Acting A/Prof.,

Filippov Buryat State Agricultural Academy

8 Pushkina St., Ulan-Ude 670024, Russia

rindaol@mail.ru

Abstract. The concept of "multiculturalism" has been actively used for more than half a century, but become particularly topical in recent decades. In a multicultural society all relations of the parties should be built in the paradigm of achieving the equality of their rights and opportunities, dialectics of human rights and his responsibility, preservation of the identity of ethnic groups and their coexistence based on the concept of human rights, inextricably linked with the requirement to all citizens to comply with the law and generally accepted rules. The success of intercultural dialogue also depends on the ability of its participants to proceed from the fundamental complementarity of interacting cultures. Russia is a multicultural country. Cultures of the peoples inhabiting it for a long time have enriched each other, and many of their elements became common heritage. Today, migrants from post-Soviet Central Asia are a significant part of newcomers; their adaptation is successfully regulated both by legislation and by the processes of their self-organization. The multicultural Republic of Buryatia having centuries-old strong traditions of tolerance and harmony between peoples is a favorable region for migrants of other cultures. 
И. 3. Чимитова. Проблема прав человека в мультикультурном обществе

Keywords: multiculturalism, human rights, legislation, migrant, host society, ethnic group, complementarity of cultures

\section{For citation}

Chimitova I. Z. Human Rights Problem in a Cultural Society. Bulletin of Buryat State University. Philosophy. 2021; 2: 61-69 (In Russ.).

The article was submitted 12.04.2021; approved after reviewing 30.04.2021; accepted for publication 11.05.2021. 